\title{
Goniothalamin induces apoptosis associated with autophagy activation through MAPK signaling in SK-BR-3 cells
}

\author{
SUKANDA INNAJAK ${ }^{1}$, WILAWAN MAHABUSRAKUM ${ }^{2}$ and RAMIDA WATANAPOKASIN ${ }^{1}$ \\ ${ }^{1}$ Department of Biochemistry, Faculty of Medicine, Srinakharinwirot University, Bangkok 10110; \\ ${ }^{2}$ Department of Chemistry, Faculty of Science, Prince of Songkla University, Hat Yai, Songkhla 90112, Thailand
}

Received November 3, 2015; Accepted February 8, 2016

DOI: 10.3892/or.2016.4655

\begin{abstract}
Goniothalamin, a plant bioactive styrly-lactone, possesses many biological activities. In the present study, the anticancer effect of goniothalamin on human breast cancer cell line SK-BR-3 was investigated. The results showed that goniothalamin induced nuclear condensation, DNA fragmentation, apoptotic bodies and mitochondrial dysfunction as determined by JC-1 staining. Goniothalamin also increased the Bax/Bcl-2 ratio and expression of cleaved caspase-7, cleaved caspase- 9 and cleaved PARP, but decreased Bcl-2 expression. In addition, goniothalamin induced apoptosis via $\mathrm{p}-\mathrm{JNK} 1 / 2$ and p-p38 upregulation and inhibited cell survival via p-ERK1/2 and p-Akt downregulation. Notably, goniothalamin induced autophagy through upregulation of Atg7, Atg12-Atg5 conjugation and LC3II. The increased p-p38 and p-JNK1/2 and decreased p-Akt may lead to autophagy induction. Therefore, goniothalamin promoted apoptosis associated with autophagy induction in SK-BR-3 cells through p-p38 and p-JNK1/2 upregulation and p-Akt downregulation. The present study indicated that goniothalamin may be further used as a potential therapeutic candidate or may offer an alternative treatment for breast cancer.
\end{abstract}

\section{Introduction}

Breast cancer is the most common invasive cancer and is the leading cause of death among females worldwide (1). In patients who are younger than 50 years, chemotherapy increases the survival rate up to 15 years $(10 \%)$, but in older women the increase is only $3 \%$ (2). However, the long-term side-effects of chemotherapy substantially affect the quality of life of these patients (3).

Apoptosis or programmed cell death is an essential physiological process that plays a critical role in development,

Correspondence to: Professor Ramida Watanapokasin, Department of Biochemistry, Faculty of Medicine, Srinakharinwirot University, Bangkok 10110, Thailand

E-mail: ramidawa@yahoo.com

Key words: goniothalamin, apoptosis, Akt, MAPK, autophagy tissue homeostasis and elimination of damaged cells. The morphological changes of apoptosis are due to the action of caspases (4). Apoptosis was initially described by its morphological characteristics, including cell shrinkage, membrane blebbing, chromatin condensation and nuclear fragmentation (5). Biochemical features associated with apoptosis include internucleosomal cleavage of DNA, phosphatidylserine (PS) externalization and plasma membrane changes (6).

Three types of cell death have been identified based on morphological criteria, including type I (apoptosis), type II (autophagic cell death) and type III (necrosis) cell death. The autophagic pathway involves the degradation of subcellular components. This process includes the formation of cytoplasmic double membrane-bound vacuoles (autophagosomes), which sequester cytosolic cargo for delivery to the lysosomes (7). The autophagy-related (Atg) proteins and microtubule-associated protein 1 light chain 3 (LC3) are major proteins involved in the processes of autophagy (8). The overexpression of the autophagic signal has been reported in various forms of cell death under certain experimental conditions resulting in autophagy-dependent cell death (9).

Goniothalamin, a plant bioactive styrly-lactone found in the family Annonaceae, has been mainly isolated from the genus Goniothalamus (10). In the present study, we used goniothalamin extracted from Goniothalamus macrophyllus that is found in the Southern part of Thailand and is known by the local name, 'Ching Dok Diao' or 'Rajchakru' (11). Goniothalamin has been shown to exhibit antimicrobial, antifungal (12) and insecticidal activity (13). Indeed, it was reported that goniothalamin inhibited cell proliferation and induced cytotoxicity in a variety of cancer cells such as cervical (14), gastric, kidney (15), leukemia (16), ovarian, melanoma, colon (17), liver (18), lung (19) and breast (20) cancer cells. Moreover, goniothalamin has been shown to possess anticancer and apoptosis-inducing properties in several types of cancer. However, the effects of goniothalamin on human HER2-overexpressing breast cancer, which grows and spreads more rapidly than other breast cancer types, have not yet been studied. Therefore, we aimed to verify the hypothesis that goniothalamin could inhibit the growth of the human breast cancer SK-BR-3 cell line through induction of apoptosis.

Our study demonstrated that goniothalamin increased the levels of cleaved-caspase-7 and -9 and cleaved PARP, decreased $\mathrm{Bcl}-2$ expression and increased the $\mathrm{Bax} / \mathrm{Bcl}-2$ ratio. 
JC-1 staining revealed that goniothalamin induced mitochondrial transmembrane dysfunction. The results also showed that goniothalamin downregulated levels of phosphorylated ERK1/2 and phosphorylated Akt. Moreover, goniothalamin induced apoptosis through upregulation of phosphorylated JNK1/2 and p38 in the SK-BR-3 cells. In addition, goniothalmin induced autophagy through upregulation of Atg7, Atg12-5 conjugation and LC3II in the SK-BR-3 cells. Our results demonstrated that goniothalamin induced apoptosis through MAPK signaling associated with autophagy induction in the SK-BR-3 cells.

\section{Materials and methods}

Materials. RPMI-1640 medium was purchased from Gibco (Grand Island, NY, USA). Hoechst 33342, fetal bovine serum (FBS), 3-(4,5-dimethylthaiazol-2-yl)-2,5-diphenyltetrazolium bromide (MTT), 5,5',6,6'-tetrachloro-1,1',3,3'-tetraethyl-imidacarbocyanine iodide (JC-1) and phenylmethylsulphonyl fluoride (PMSF) were purchased from Sigma-Aldrich (St. Louis, MO, USA). Dimethyl sulfoxide (DMSO) was purchased from Merck Calbiochem (San Diego, CA, USA). Guava Cell $\mathrm{Cycle}^{\circledR}$ reagent for cell cycle analysis was purchased from Merck Millipore Corp., Merck KGaA (Darmstadt, Germany). MEK1/2 inhibitor (U0126) was purchased from Cell Signaling Technology, Inc. (Danvers, MA, USA). Goniothalamin was obtained from Associate Professor Wilawan Mahabusarakam, Faculty of Science, Prince of Songkla University, Thailand in purified powder form. It was extracted from the stems of Goniothalamus macrophyllus which was collected from Songkhla Province Thailand in September, 2007. Identification was made by Mr Ponlawat Pattarakulpisutti, Department of Biology, Faculty of Science, Prince of Songkla University. Goniothalamin was dissolved and diluted in DMSO at the desired concentration for the assays.

Cell culture. Breast cancer cell line SK-BR-3 was obtained from the American Type Culture Collection (ATCC; Manassas, VA, USA). The cells were maintained as a monolayer in RPMI-1640 medium supplemented with $10 \%$ FBS, $100 \mathrm{U} / \mathrm{ml}$ penicillin and $100 \mu \mathrm{g} / \mathrm{ml}$ streptomycin (PAA Laboratories, Pasching, Austria). The cells were cultured in $5 \% \mathrm{CO}_{2}$ at $37^{\circ} \mathrm{C}$, and after reaching $\sim 90 \%$ confluency, the cells were subcultured and the medium was replaced 2-3 times/week.

Cell proliferation and cell viability assays. The cytotoxicity of goniothalamin was determined by cell proliferation analysis using MTT assay. The cells were seeded in a 96-well plate $\left(5 \times 10^{3}\right.$ cells/well) and allowed to grow for $24 \mathrm{~h}$. The cells were then treated with goniothalamin at various concentrations, whereas the control group was treated with DMSO. After incubation for $24 \mathrm{~h}, 100 \mu \mathrm{l}$ of $0.5 \mathrm{mg} / \mathrm{ml}$ MTT solution was added to each well, and the plate was further incubated for $2 \mathrm{~h}$ at $37^{\circ} \mathrm{C}$. The supernatant was removed, and $100 \mu \mathrm{l}$ of DMSO was added to each well to solubilize the water insoluble purple formazan crystals. The absorbance was measured using a microplate reader at $570 \mathrm{~nm}$ (Multiskan EX; Thermo Electron Corp., Vantaa, Finland), and the $\mathrm{IC}_{50}$ value was calculated using the software GraphPad Prism 3.03 (GraphPad Software, Inc., San Diego, CA, USA).
The effect of goniothalamin on cell viability at different times and doses was determined. The cells were treated with goniothalamin at various concentrations of 5, 10, 15 and $20 \mu \mathrm{g} / \mathrm{ml}$, whereas the control group was treated with DMSO. After incubation for 3, 6, 9, 12 and $24 \mathrm{~h}$, cell viability was determined by the MTT assay. Survival percentage (\%) of the cells was calculated relative to the control. Cell viability was assessed in three independent experiments.

Nuclear morphological staining with Hoechst 33342. SK-BR-3 cells were seeded at $3 \times 10^{5} / 35-\mathrm{mm}$ dish for $24 \mathrm{~h}$. The cells were treated with $20 \mu \mathrm{g} / \mathrm{ml}$ goniothalamin for 3, 6,9 and $12 \mathrm{~h}$. As control, the cells were treated with $0.02 \%$ DMSO for $24 \mathrm{~h}$. Subsequently, the cells were stained with $10 \mu \mathrm{M}$ Hoechst 33342 for $30 \mathrm{~min}$ at $37^{\circ} \mathrm{C}$ and examined under a fluorescence microscope (IX73; Olympus, Tokyo, Japan).

Cell cycle analysis. To examine apoptosis, the SK-BR-3 cells were treated with $20 \mu \mathrm{g} / \mathrm{ml}$ goniothalamin. The cells were harvested after drug treatment and washed with phosphatebuffered saline (PBS). The cells were fixed with $70 \%$ ethanol at $4^{\circ} \mathrm{C}$ for $>1 \mathrm{~h}$. Then, the cells were stained according to the manufacturer's instructions (Guava Cell Cycle ${ }^{\circledR}$ reagent from Merck Millipore Corp., Merck KGaA. The DNA content was observed using the Guava EasyCyte ${ }^{\mathrm{TM}}$ flow cytometer and GuavaSoft $^{\mathrm{TM}}$ software (Merck Millipore Corp., Merck KGaA).

Measurement of mitochondrial membrane potential $(\Delta \Psi m)$. The $\Delta \Psi \mathrm{m}$ was determined using the potential sensitive dye JC-1, which is a lipophilic cation that is incorporated into the mitochondrial membrane. The cells were seeded at $3 \times 10^{5} / 35-\mathrm{mm}$ dish for $24 \mathrm{~h}$ and treated with $20 \mu \mathrm{g} / \mathrm{ml}$ goniothalamin for 3,6 and $9 \mathrm{~h}$, and the control cells were treated with $0.02 \%$ DMSO. The cells were then stained with $5 \mu \mathrm{g} /$ $\mathrm{ml}$ of JC-1 in the dark at $37^{\circ} \mathrm{C}$ for $15 \mathrm{~min}$ before analysis by fluorescence microscopy (IX73).

Western blot analysis. The SK-BR-3 cells were seeded at $3 \times 10^{5} / 35-\mathrm{mm}$ dish for $24 \mathrm{~h}$, and treated with $20 \mu \mathrm{g} / \mathrm{ml}$ goniothalamin, and harvested at designated time points. Then, the cells were lysed with RIPA lysis buffer (50 mM Tris-HCL, $\mathrm{pH} 7.5,5 \mathrm{mM}$ EDTA, $250 \mathrm{mM} \mathrm{NaCl}, 0.5 \%$ Triton X-100) supplemented with $10 \mathrm{mM}$ PMSF and Complete Mini Protease Inhibitor Cocktail (Roche Diagnostics GmbH, Mannheim, Germany). The supernatants were prepared by centrifugation, and the protein content was determined using a protein assay kit (Bio-Rad Laboratories, USA). The total protein extracts were separated by $8-12 \%$ SDS-PAGE and transferred onto polyvinylidene fluoride (PVDF) membranes (GE Healthcare, Buckinghamshire, UK) for $1-2 \mathrm{~h}$ at $100 \mathrm{~V}$ using a Mini Trans-Blot Cell (Bio-Rad Laboratories). The membranes were blocked with $5 \%$ non-fat dry milk in Tris-buffered saline and Tween-20 (TBST) (10 mM Tris, $\mathrm{pH} \mathrm{7.5,} 150 \mathrm{mM} \mathrm{NaCl}$ and $0.1 \%$ Tween-20) for $1 \mathrm{~h}$ at room temperature and incubated overnight at $4^{\circ} \mathrm{C}$ with the primary antibody (Cell Signaling Technology, Beverly, MA, USA). Membranes were washed three times in TBST buffer, followed by incubation for $1 \mathrm{~h}$ at room temperature with the corresponding HRP-linked secondary antibodies. The specific protein bands were detected by chemiluminescent HRP substrate (Merck Millipore Corp., 


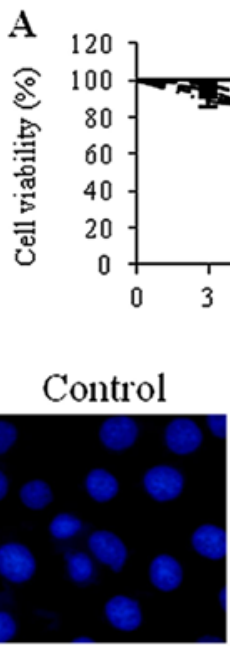

\section{B}

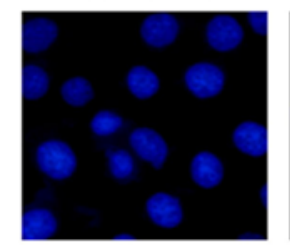

$3 \mathrm{~h}$
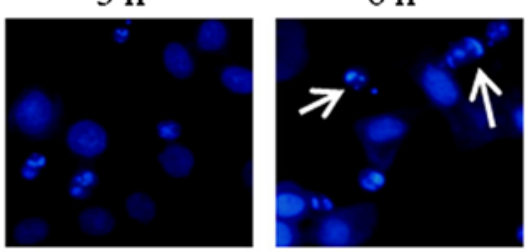

$9 \mathrm{~h}$
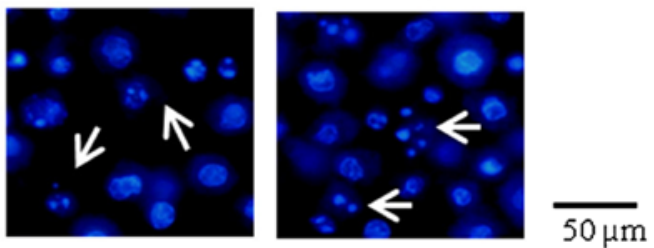

C

Control
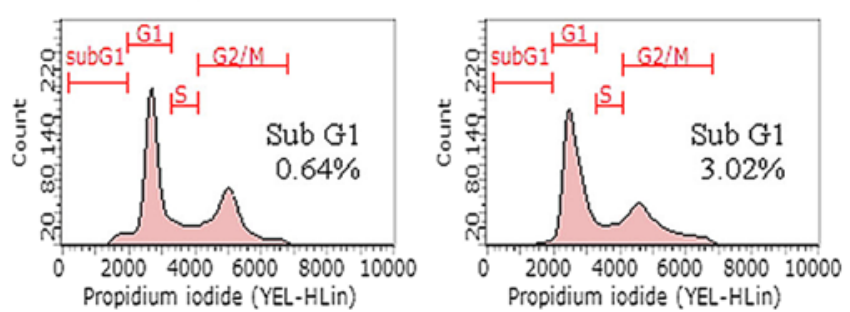

$24 \mathrm{~h}$

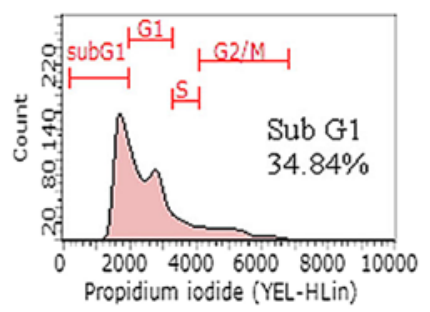

Figure 1. Effect of goniothalamin on cell viability and apoptosis induction. (A) Time- and dose-dependent effect of goniothalamin on SK-BR-3 cell viability following treatment with different concentrations of goniothalamin at several time points. (B) Effects of goniothalamin on nuclear condensation of SK-BR-3 cells. Cells were treated with $20 \mu \mathrm{g} / \mathrm{ml}$ goniothalamin for $3,6,9$ and $12 \mathrm{~h}$ and then stained with Hoechst 33342 and examined under a fluorescent microscope (magnification, $x 40$ ). (C) The sub-G1 peak formed with reduced DNA content represented the presence of apoptotic cells. The mean apoptotic population of SK-BR-3 cells was $0.64 \%$ under the control condition, while it was increased to 3.02 and $34.84 \%$ after treatment with $20 \mu \mathrm{g} / \mathrm{ml}$ goniothalamin for 12 and $24 \mathrm{~h}$, respectively.

Merck KGaA) and detected under a chemiluminescent imaging system (GeneGnome Gel Documentation; Synoptics Ltd., Cambridge, UK).

Statistical analysis. All data presented were obtained from at least three independent experiments and are presented as mean \pm standard deviation (SD). Statistical significance was
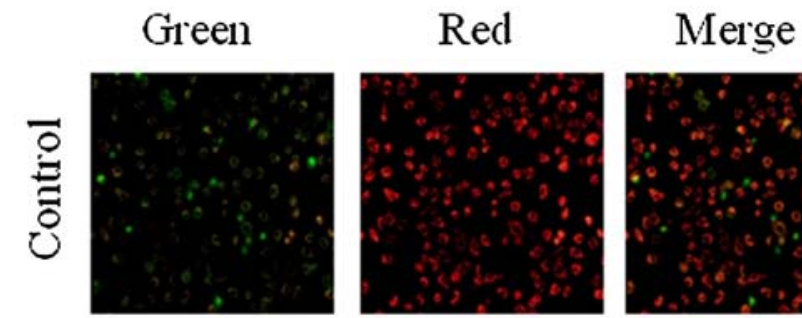

$3 \mathrm{~h}$
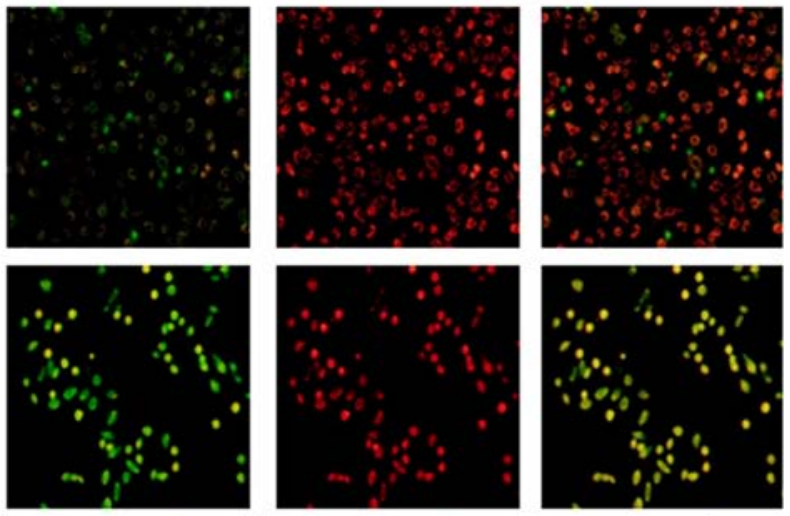

$6 \mathrm{~h}$
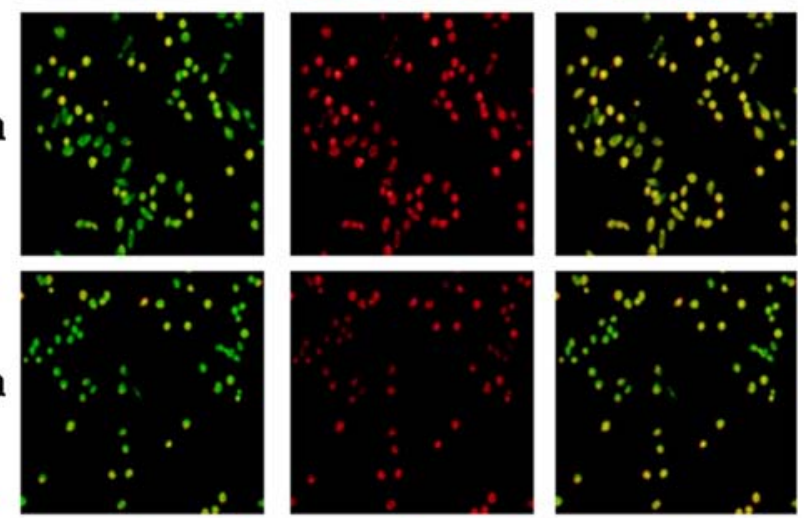

$9 \mathrm{~h}$
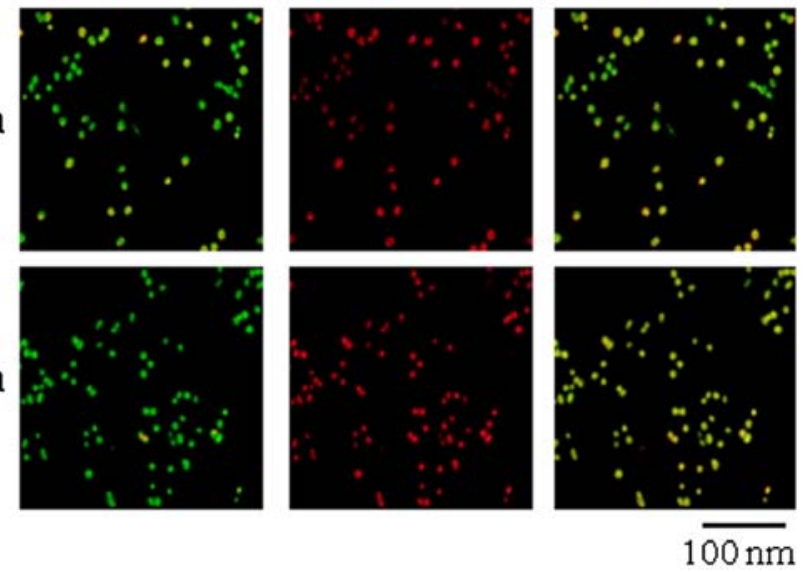

Figure 2. Effect of gonothalamin on mitochondrial membrane potential in SK-BR-3 cells. Cells were treated with $20 \mu \mathrm{g} / \mathrm{ml}$ goniothalamin for 3,6 and $9 \mathrm{~h}$. Red fluorescence in the control cells (0.02\% DMSO) indicated high membrane potential and green fluorescence in the goniothalamin-treated cells indicated loss of membrane potential. The goniothalamin-treated cells showed an increased green/red fluorescence intensity ratio in a timedependent manner (magnification, x40).

assessed by one-way analysis of variance (ANOVA). Statistical analysis was performed using SPSS statistical software package (version 11.5) also carried out using the software GraphPad Prism 3.03 (GraphPad Software, Inc.). The western blotting band intensity was quantified by ImageJ densitometer. An asterisk indicates that the experimental values are significantly different from those of the control $(\mathrm{p}<0.05)$.

\section{Results}

Goniothalamin inhibits cell viability and induces apoptosis in SK-BR-3 human breast cancer cells. The antiproliferative activity of goniothalamin in the SK-BR-3 cells was determined by MTT assay. The $\mathrm{IC}_{50}$ value was $10 \pm 0.45 \mu \mathrm{g} /$ $\mathrm{ml}$. Goniothalamin inhibited cell viability in a dose- and time-dependent manner. Treatment of SK-BR-3 cells with $20 \mu \mathrm{g} / \mathrm{ml}$ goniothalamin for $12 \mathrm{~h}$ reduced cell viability to $\sim 20 \%$ comparing with that noted in the control cells (Fig. 1A).

To determine the antiproliferation and cell death induction mediated by goniothalamin, Hoechst 33342 staining was carried out. The results showed that goniothalamin induced chromatin condensation and DNA fragmentation, characteristics of apoptotic cells (Fig. 1B). 


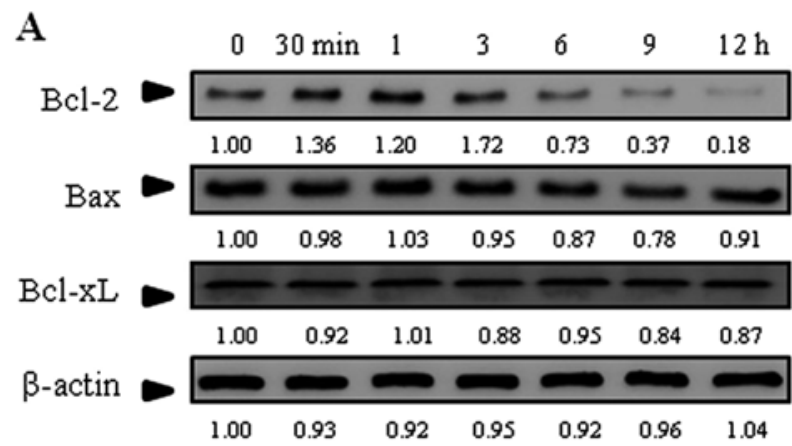

B
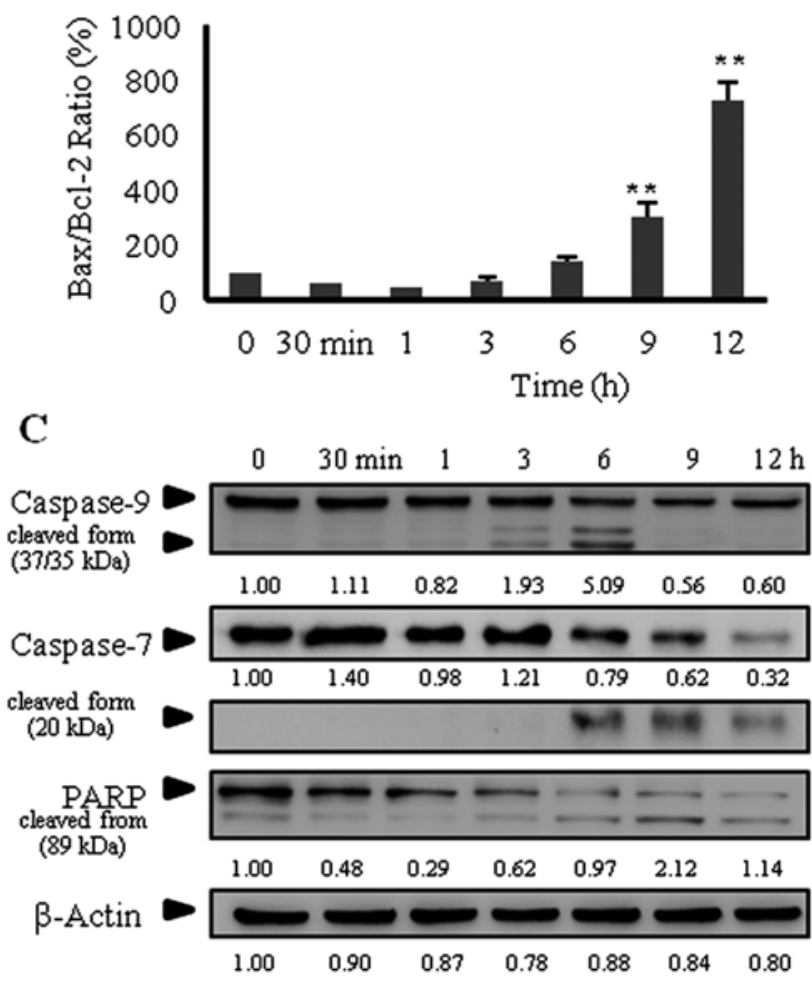

Figure 3. Effect of goniothalamin on apoptotic protein expression. Cells were treated with $20 \mu \mathrm{g} / \mathrm{ml}$ goniothalamin for $30 \mathrm{~min}, 1,3,6,9$ and $12 \mathrm{~h}$. (A) Effect of goniothalamin on Bcl-2 family proteins in SK-BR-3 cells was determined by western blot analysis. (B) Goniothalamin-treated cells showed a significant increase in the Bax/Bcl-2 ratio at $9 \mathrm{~h}$ in the SK-BR-3 cells. (C) Effects of goniothalamin on activation of caspase- 9 and -7 , and cleaved PARP in the SK-BR-3 cells using $\beta$-actin as an internal control. The quantitative data are expressed as the mean $\pm \mathrm{SD}, \mathrm{n}=3$. ${ }^{*} \mathrm{p}<0.05,{ }^{* *} \mathrm{p}<0.01$ significant difference compared with the control.

Effect of goniothalamin on cell cycle distribution. The effect of goniothalamin on the cell cycle showed that goniothalamin alone did not increase the sub-G1 population. In contrast, the goniothalamin-treated cells showed an increase in the sub-G1 population to 3.02 and $34.84 \%$ after treatment with $20 \mu \mathrm{g} / \mathrm{ml}$ goniothalamin for 12 and $24 \mathrm{~h}$, respectively (Fig. 1C).

Effect of goniothalamin on $\Delta \Psi m$. During apoptosis, several key events occur in the mitochondria. Bax forms oligomers on the mitochondrial membrane leading to changes in electron transport and loss of $\Delta \Psi \mathrm{m}$. JC-1 is a cytofluorimetric, lipophilic cationic dye that can selectively enter into mitochondria and reversibly change color from green to red as the membrane potential increases. In healthy cells with high $\Delta \Psi \mathrm{m}$, JC-1

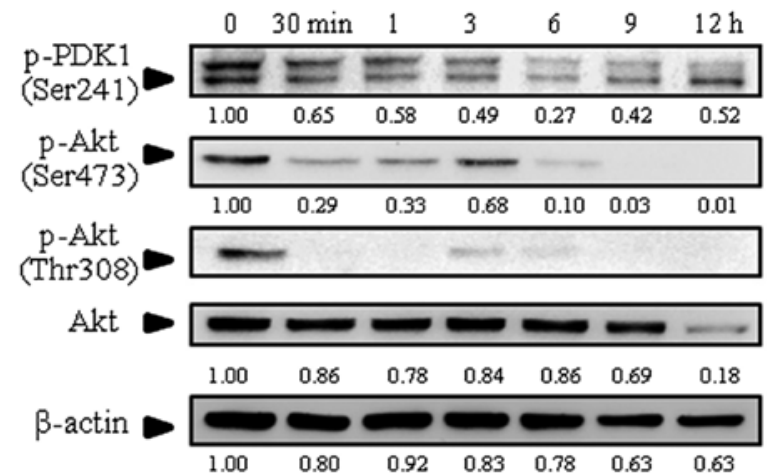

Figure 4. Effect of goniothalamin on Akt signaling molecules in the SK-BR-3 cells. Cells were treated with $20 \mu \mathrm{g} / \mathrm{ml}$ goniothalamin and the levels of p-PDK1, p-Akt at Ser473 and p-Akt at Thr 308 and total Akt were measured. $\beta$-actin was used as an internal control.

spontaneously forms complexes known as J-aggregates with intense red fluorescence. In contrast, in apoptotic or unhealthy cells with low $\Delta \Psi \mathrm{m}, \mathrm{JC}-1$ remains in the monomeric form, which shows only green fluorescence. The ratio of green to red fluorescence is dependent only on the $\Delta \Psi \mathrm{m}$. The results showed that SK-BR-3 cells treated with goniothalamin for 3, 6 and $9 \mathrm{~h}$ had an increased green/red ratio, while the control cells showed red fluorescence (Fig. 2) indicating that goniothalamin induced the loss of $\Delta \Psi \mathrm{m}$ in the SK-BR-3 cells.

Effect of goniothalamin on the expression of Bcl-2 family proteins, caspase-7 and -9, and cleaved PARP activation. The Bcl-2 family proteins have expanded significantly and are composed of both pro-apoptotic and anti-apoptotic molecules. To determine whether goniothalamin induces apoptosis through the mitochondrial apoptotic pathway, we examined the expression of the Bcl-2 family proteins. As shown in Fig. 3A, goniothalamin decreased Bcl-2 expression at $6 \mathrm{~h}$, while it increased the Bax/Bcl-2 ratio at $9 \mathrm{~h}$ (Fig. 3B). These results indicate that goniothalamin induced apoptosis through the mitochondrial pathway.

Caspase expression was also determined by western blot analysis. The results showed that goniothalamin induced caspase- 9 and -7 cleavage after 3 and $6 \mathrm{~h}$ of treatment (Fig. 3C). The maximal induction of cleaved caspase- 9 was at $6 \mathrm{~h}$, and then was markedly decreased at 9 and $12 \mathrm{~h}$. In addition, cleaved caspase-7 was maximally activated at $6 \mathrm{~h}$ and was decreased at 9 and $12 \mathrm{~h}$, which was correlated with the expression of the proform. Ferguson et al showed that apoptosis induction in MCF-7 was independent of caspase-9 expression. Caspase-7 expression was not correlated with caspase-9 expression for apoptosis induction in MCF-7 cells (21). Hakem et al also showed that caspase- 9 deficiency could not protect cells from apoptosis induced by $\alpha$-CD95 and could not protect caspase-3 activation in vivo (22). Moreover, goniothalamin induced cleaved PARP activation downstream of caspase. The results indicated that goniothalamin induced apoptosis mediated by caspases and PARP through the intrinsic apoptosis pathway (via caspase-9).

Effect of goniothalamin on expression of Akt. Akt plays a key role in multiple cellular processes such as cell growth, cell 


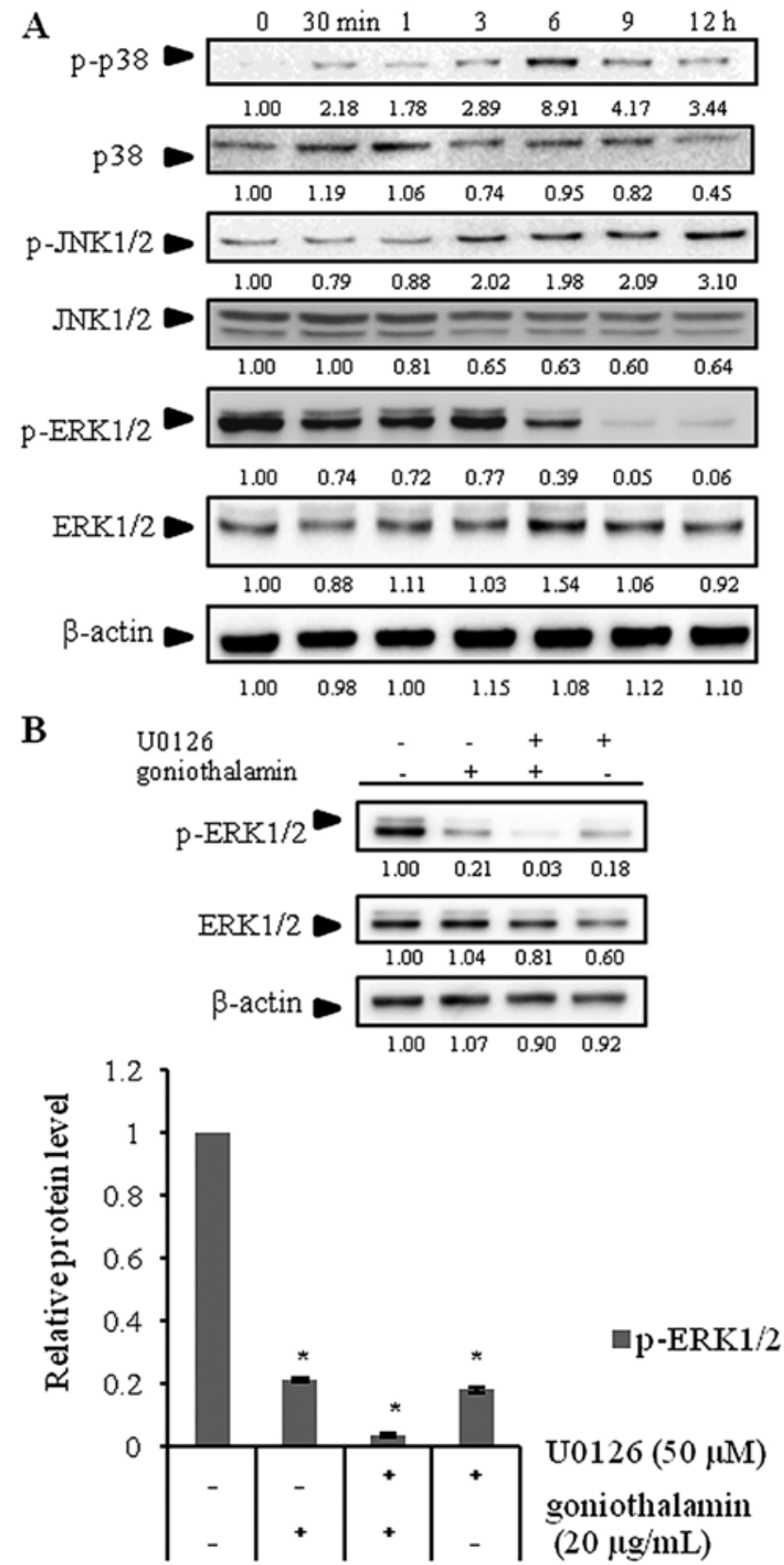

Figure 5. Effects of goniothalamin on phosphorylation of MAPK(s) signaling in SK-BR-3 cells. (A) Cells were treated with $20 \mu \mathrm{g} / \mathrm{ml}$ goniothalamin for $30 \mathrm{~min}, 1,3,6,9$ and $12 \mathrm{~h}$ and examined by western blot analysis. $\beta$-actin was used as the internal control. (B) U0126 was used as a positive control compared with the goniothalamin treatment. "p $<0.05$ significant difference compared with the control.

proliferation, transcription and cell migration. PDK activates Akt by phosphorylation at Thr308 and Ser473. The results showed that levels of phosphorylated Akt (p-Akt) at Thr308 and Ser473 were decreased as well as phosphorylated PDK1 (p-PDK1) at Ser241 (Fig. 4), suggesting that goniothalamin inhibited cell survival by downregulation of $\mathrm{p}$-Akt expression in the SK-BR-3 cells.

Effect of goniothalamin on expression of MAPKs. MAPK pathways are evolutionarily conserved kinases, which link extracellular signals to the machinery that controls fundamental cellular processes such as growth, proliferation, differentiation,

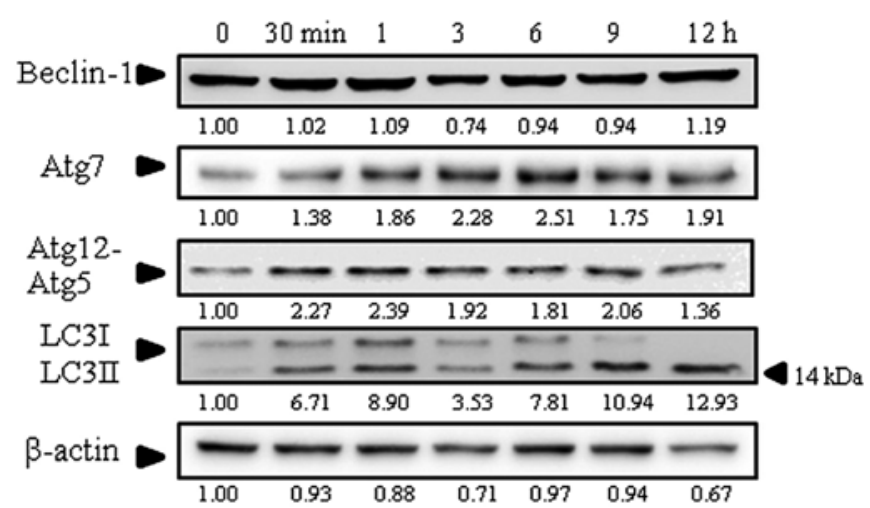

Figure 6. Effect of goniothalamin on autophagy signaling molecules in SK-BR-3 cells. Cells were treated with $20 \mu \mathrm{g} / \mathrm{ml}$ goniothalamin and the levels of Beclin-1, Atg7, Atg12-5 conjugation and LC3II were measured. $\beta$-actin was used as an internal control.

migration and apoptosis. There is a three-step kinase module in which a MAPK is activated upon phosphorylation by a MAPKK, which in turn is activated when phosphorylated by a MAPKKK. Our results showed an increase in phosphorylated JNK1/2 (p-JNK1/2) and phosphorylated p38 (p-p38) expression, but a decrease in phosphorylated ERK1/2 (p-ERK1/2) expression in the SK-BR-3 cells following goniothalamin treatment (Fig. 5A). In addition, a MEK1/2 inhibitor (U0126) simultaneously blocked p-ERK1/2 indicating that goniothalamin inhibited cell survival through ERK signaling (Fig. 5B). These results demonstrated that goniothalamin induced apoptosis by inhibiting cell survival through p-ERK1/2 activation.

Effect of goniothalamin on autophagy induction. For autophagy induction, the protein level of LC3II, which is a protein marker of autophagy, was determined. As shown in Fig. 6, the LC3II level was increased in the SK-BR-3 cells treated with goniothalamin. In addition, the levels of Atg7 and Atg12-Atg5 conjugation were upregulated while no effect was noted on Beclin-1. These results demonstrated that goniothalmin induced autophagy in the SK-BR-3 cells through the upregulation of LC3II, Atg7 and Atg12-Atg5 conjugation.

\section{Discussion}

Recent research has demonstrated the cytotoxicity and antitumor properties of goniothalamin against various human tumor cell lines such as A-549 (lung carcinoma), HL-60 (promyelocytic leukemia) and SGC-7901 (stomach cancer) (23). It also induced apoptosis in cancer cells such as HeLa (cervical cancer), HT29 (colon cancer) (24), Ca9-22 (oral cancer) (25), HepG2 (hepatoblastoma), and invasive breast carcinoma MDA-MB-231 cell lines (26). However, the mechanisms of apoptosis induction in breast cancer SK-BR-3 cells have not yet been reported.

The results showed that goniothalamin inhibited SK-BR-3 cell growth in a time- and dose-dependent manner with an $\mathrm{IC}_{50}$ value of $10 \pm 0.45 \mu \mathrm{g} / \mathrm{ml}$ (Fig. 1A). To confirm apoptosis induction, we investigated characteristic morphological changes including cell shrinkage, membrane blebbing, 
chromatin condensation and formation of apoptotic bodies. Hoechst 33342 staining revealed condensed chromatin and apoptotic bodies in the SK-BR-3 cells following treatment with goniothalamin (Fig. 1B). The population of sub-G1 cells indicated apoptotic cell death (Fig. 1C). Furthermore, the effect of goniothalamin on the mitochondrial membrane potential $(\Delta \Psi \mathrm{m})$ dysfunction in SK-BR-3 cells was detected by increased green/red fluorescence ratio at $3 \mathrm{~h}$ (Fig. 2). Loss of the $\Delta \Psi \mathrm{m}$ and release of sequestered pro-apoptotic proteins from the intermembranous space into the cytosol stimulates apoptosome formation followed by activation of caspase-9 (27).

It is well-known that the apoptosis signaling pathway consists of two main pathways: extrinsic and intrinsic pathways. Our results showed that goniothalamin decreased Bcl-2 expression (Fig. 3A) and increased the Bax/Bcl-2 ratio (Fig. 3B) in SK-BR-3 cells. These events suggested that goniothalamin induced apoptosis through the intrinsic pathway. Inayat-Hussain et al reported that goniothamin did not alter the level of Bcl-2 expression in Jurkat cells. Then, Bcl-2-overexpressed Jurkat cells were used to demonstrate the effects of Bcl-2 on cell death by MTT assay. They found that $\mathrm{Bcl}-2$ overexpression did not protect the cells from the cytotoxic effects of goniothalamin (28). This discrepancy is likely due to the different cell types examined, as Jurkat cells (T-lymphocyte) are suspension cells whereas SK-BR-3 (breast cancer) are adherent cells. In addition, they possess different receptors on the cell surface; thus they responded differently. Another study showed that goniothalamin induced apoptosis via Bcl-2 inactivation by JNK1/2. JNK1/2 phosphorylated Bcl-2 (Ser70, Ser87 and Thr69) leading to inactivation of the anti-apoptotic function (29).

The control and regulation of these apoptotic mitochondrial events occurs through members of the Bcl-2 family proteins. Anti-apoptotic Bcl-2 proteins exert their activity by binding to the pro-apoptotic members Bax and Bak, preventing mitochondrial damage (30). Thus, decreased Bcl-2 was associated with mitochondrial dysfunction and led to apoptosis. To confirm whether the apoptosis induction by goniothalamin was caspase-dependent, we examined the active forms of caspases by western blot analysis. The effect of goniothalamin on PARP activity was also determined. The results indicated that treatment with $20 \mu \mathrm{g} / \mathrm{ml}$ goniothalamin induced cleaved caspase-9, and -7, and cleaved PARP expression in the SK-BR-3 cells (Fig. 3C). The initiator caspase-9 causes the activation of the effector caspases $(-3,-6$ and -7$)$, which cleave vital substrates including PARP, resulting in cellular death. PARP plays an important role in DNA repair and the activation of cellular defense mechanisms against DNA damage. PARP is inactivated by caspase cleavage via caspase-3 or -7 . The size of the cleaved fragments $(89 \mathrm{kDa})$ can provide insight into which enzyme is responsible for the cleavage, and can be useful in determining which cell death pathway has been activated (31). In HeLa cells, goniothalamin was reported to induce apoptosis through caspase-9 activity (32). Moreover, goniothalamin induced caspase- 3 and cleaved PARP expression in breast cancer MDA-MB-231 cells treated with $30 \mu \mathrm{M}$ goniothalamin for $48 \mathrm{~h}$ (26).

Akt upregulation is likely to be viewed as a compensatory protective mechanism of cells for escaping death, and the fully active Akt mediates numerous cellular functions leading to cell survival (33). Our results showed that goniothalamin inhibited cell survival via p-Akt downregulation (Fig. 4), which corresponded with a previous study that the anticancer mechanism of RA-V was related to the blockage of PDK1 and Akt interaction leading to apoptosis induction (34).

The MAPK kinase family plays a critical role in cell survival and cell death. Conventional MAPKs in mammalian cells include ERK1/2, JNK1/2 and p38, which are activated through a specific phosphorylation cascade. Active ERK1/2 phosphorylates numerous cytoplasmic and nuclear targets, including kinases, phosphatases, transcription factors and cytoskeletal proteins (35). It is well-known that ERK1/2 promotes cell survival, while JNK1/2 and p38 induce apoptosis. Dunn et al reported that the presence of the ERK signaling pathway depends on the particular cell type, and progresses to regulate proliferation, differentiation, survival, migration, angiogenesis and chromatin remodeling (36). ERK1/2 can also promote cell survival by upregulation of anti-apoptotic molecules via enhancement of their activities or activation of their transcription. JNK $1 / 2$ can activate transcriptional factors including c-Jun and AP1, whereas their tumor-suppressive functions are probably related to their pro-apoptotic activity (37). In the present study, goniothalamin downregulated p-ERK1/2 at $6 \mathrm{~h}$, but upregulated p-JNK1/2 and p-p38 at 3 and $6 \mathrm{~h}$, respectively (Fig. 5A). Indeed, we also confirmed that goniothalamin in combination with U0126, an ERK inhibitor, suppressed p-ERK1/2 activation (Fig. 5B). These results demonstrated that goniothalamin induced apoptosis via p-JNK1/2 and p-p38 upregulation and inhibited cell survival via $\mathrm{p}$-ERK1/2 downregulation.

Notably, goniothalamin showed autophagy induction through upregulation of Atg7, Atg12-Atg5 conjugation and LC3II (Fig. 6) in a time- and dose-dependent manner indicating autophagic cell death associated with the elevation of autophagosome formation. These results were supported by a previous study that Atg12-Atg5 conjugation and the conversion of LC3I to LC3II indicate autophagic activity (38). In addition, another function of Atg12 is to stimulate mitochondrial apoptosis by inactivating Bcl-2 and Mcl-1 (39). Therefore, our findings showed that goniothalamin induced apoptosis and autophagy which are processes of programmed cell death and interplay with each other (40). The Atg family and LC3 are key proteins involved in the autophagy signaling pathway. The conversion of LC3I (16 kDa) to LC3II (14 kDa) is used as a common indicator of autophagy detection (41). In addition, our results showed that goniothalamin induced $\mathrm{p}-\mathrm{p} 38$ and p-JNK1/2 upregulation and p-Akt downregulation in the SK-BR-3 cells. These results correlated with previous reseach that found that baicalin induced autophagy accompanied by downregulation of the p-Akt (Ser473) level leading to increased Atg5, Atg7 and Atg12 and then the conversion of LC3I to LC3II and finally autophagy induction (42). Increased p-p38 leading to inhibition or induction of autophagy depends on the cellular context and cell type (43). Alisertib was reported to increase the p-p38 level correlated with highly accumulated LC3II in MCF-7 and MDA-MB-231 cells (44). Furthermore, graphene quantum dots (GQDs) significantly increased p-p38 which was correlated with increased Beclin-1 and LC3II (43). In addition, increased p-JNK1/2 activation occurred upstream of the autophagy induction when cells were starved (45). 
Furthermore, p-JNK1/2 activation led to Bcl-2 phosphorylation at Thr69, Ser70 and Ser87 which dissociated Bcl-2 from Beclin-1 leading to autophagy progression. Activation of p-JNK1/2 induces FoxOs nuclear localization and increases ATG gene transcription (46). Thus, goniothalamin induced apoptosis through an increase in cleaved caspase-9, cleaved caspase-7, p-JNK1/2 and p-p38 activation as well as p-ERK1/2 and p-Akt suppression. In addition, p-p38 and p-JNK1/2 upregulation and Akt downregulation may lead to autophagy.

In conclusion, goniothalamin induced apoptosis associated with autophagy through p-p38 and p-JNK1/2 upregulation and Akt downregulation in SK-BR-3 cells. Our findings imply that goniothalamin may be used as an anticancer drug candidate for the treatment of human breast cancer.

\section{Acknowledgements}

We would like to thank the Royal Golden Jubilee Ph.D. Program (grant no. PHD/0218/2552), the Thailand Research Fund, the Strategic Wisdom and Research Institute, the Srinakharinwirot University and Research Division, and the Faculty of Medicine, Srinakharinwirot University for their support.

\section{References}

1. Jemal A, Bray F, Center MM, Ferlay J, Ward E and Forman D: Global cancer statistics. CA Cancer J Clin 61: 69-90, 2011.

2. Early Breast Cancer Trialists' Collaborative Group (EBCTCG): Effects of chemotherapy and hormonal therapy for early breast cancer on recurrence and 15-year survival: An overview of the randomised trials. Lancet 365: 1687-1717, 2005.

3. Eifel P, Axelson JA, Costa J, Crowley J, Curran WJ Jr, Deshler A, Fulton S, Hendricks CB, Kemeny M, Kornblith AB, et al: National Institutes of Health Consensus Development Conference Statement: Adjuvant therapy for breast cancer, November 1-3, 2000. J Natl Cancer Inst 93: 979-989, 2001.

4. Burz C, Berindan-Neagoe I, Balacescu O and Irimie A: Apoptosis in cancer: Key molecular signaling pathways and therapy targets. Acta Oncol 48: 811-821, 2009.

5. Lowe SW and Lin AW: Apoptosis in cancer 21: 485-495, 2000.

6. Zimmermann KC, Bonzon C and Green DR: The machinery of programmed cell death. Pharmacol Ther 92: 57-70, 2001.

7. Ravikumar B, Sarkar S, Davies JE,Futter M, Garcia-Arencibia M, Green-Thompson ZW, Jimenez-Sanchez M, Korolchuk VI, Lichtenberg M, Luo S, et al: Regulation of mammalian autophagy in physiology and pathophysiology. Physiol Rev 90: 1383-1435, 2010.

8. Mizushima N: The role of the Atg1/ULK1 complex in autophagy regulation. Curr Opin Cell Biol 22: 132-139, 2010.

9. Kroemer G and Levine B: Autophagic cell death: The story of a misnomer. Nat Rev Mol Cell Biol 9: 1004-1010, 2008.

10. Blázquez MA, Bermejo A, Zafra-Polo MC and Cortes D: Styryllactones from Goniothalamus species - A review. Phytochem Anal 10: 161-170, 1999.

11. Wattanapiromsakul C, Wangsintaweekul B, Sangprapan P, Itharat A and Keawpradub N: Goniothalamin, a cytotoxic compound, isolated from Goniothalamus macrophyllus (Blume) Hook. f. \& Thomson var. macrophyllus. Warasan Songkhla Nakharin 27: 479-487, 2005.

12. Barcelos RC, Pastre JC, Caixeta V, Vendramini-Costa DB, de Carvalho JE and Pilli RA: Synthesis of methoxylated goniothalamin, aza-goniothalamin and $\gamma$-pyrones and their in vitro evaluation against human cancer cells. Bioorg Med Chem 20: 3635-3651, 2012.

13. Bruder M, Vendramini-Costa DB, de Carvalho JE and Pilli RA: Design, synthesis and in vitro evaluation against human cancer cells of 5-methyl-5-styryl-2,5-dihydrofuran-2-ones, a new series of goniothalamin analogues. Bioorg Med Chem 21: 5107-5117, 2013.
14. Ali AM, Mackeen MM, Hamid M, Aun QB, Zauyah Y, Azimahtol HL and Kawazu K: Cytotoxicity and electron microscopy of cell death induced by goniothalamin. Planta Med 63: 81-83, 1997.

15. Fátima A, Kohn LK, Carvalho JE and Pilli RA: Cytotoxic activity of $(S)$-goniothalamin and analogues against human cancer cells. Bioorg Med Chem 14: 622-631, 2006.

16. Inayat-Hussain SH, Wong LT, Chan KM, Rajab NF, Din LB, Harun R, Kizilors A, Saxena N, Mourtada-Maarabouni M, Farzaneh F, et al: RACK-1 overexpression protects against goniothalamin-induced cell death. Toxicol Lett 191: 118-122, 2009.

17. de Fátima A, Kohn LK, Antônio MA, de Carvalho JE and Pilli RA: $(R)$-Goniothalamin: Total syntheses and cytotoxic activity against cancer cell lines. Bioorg Med Chem 13: 2927-2933, 2005

18. Al-Qubaisi M, Rozita R, Yeap SK, Omar AR, Ali AM and Alitheen NB: Selective cytotoxicity of goniothalamin against hepatoblastoma HepG2 cells. Molecules 16: 2944-2959, 2011

19. Chiu CC, Liu PL, Huang KJ, Wang HM, Chang KF, Chou CK, Chang FR, Chong IW, Fang K, Chen JS, et al: Goniothalamin inhibits growth of human lung cancer cells through DNA damage, apoptosis, and reduced migration ability. J Agric Food Chem 59: 4288-4293, 2011.

20. Pihie AH, Stanslas J and Din LB: Non-steroid receptor-mediated antiproliferative activity of styrylpyrone derivative in human breast cancer cell lines. Anticancer Res 18: 1739-1743, 1998.

21. Ferguson HA, Marietta PM and Van Den Berg CL: UV-induced apoptosis is mediated independent of caspase-9 in MCF-7 cells: A model for cytochrome $c$ resistance. J Biol Chem 278: 45793-45800, 2003.

22. Hakem R, Hakem A, Duncan GS, Henderson JT, Woo M, Soengas MS, Elia A, de la Pompa JL, Kagi D, Khoo W, et al: Differential requirement for caspase 9 in apoptotic pathways in vivo. Cell 94: 339-352, 1998.

23. Zhou FS, Tang WD, Mu Q, Yang GX, Wang Y, Liang GL and Lou LG: Semisynthesis and antitumor activities of new styryl-lactone derivatives. Chem Pharm Bull (Tokyo) 53: 1387-1391, 2015.

24. Alabsi AM, Ali R, Ali AM, Al-Dubai SA, Harun H, Abu Kasim NH and Alsalahi A: Apoptosis induction, cell cycle arrest and in vitro anticancer activity of gonothalamin in a cancer cell lines. Asian Pac J Cancer Prev 13: 5131-5136, 2012.

25. Yen CY, Chiu CC, Haung RW, Yeh CC, Huang KJ, Chang KF, Hseu YC, Chang FR, Chang HW and Wu YC: Antiproliferative effects of goniothalamin on Ca9-22 oral cancer cells through apoptosis, DNA damage and ROS induction. Mutat Res 747: 253-258, 2012.

26. Chen WY, Wu CC, Lan YH, Chang FR, Teng CM and Wu YC: Goniothalamin induces cell cycle-specific apoptosis by modulating the redox status in MDA-MB-231 cells. Eur J Pharmacol 522: 20-29, 2005.

27. Cory S and Adams JM: The Bcl2 family: Regulators of the cellular life-or-death switch. Nat Rev Cancer 2: 647-656, 2002.

28. Inayat-Hussain SH, Chan KM, Rajab NF, Din LB, Chow SC, Kizilors A, Farzaneh F and Williams GT: Goniothalamininduced oxidative stress, DNA damage and apoptosis via caspase-2 independent and Bcl-2 independent pathways in Jurkat T-cells. Toxicol Lett 193: 108-114, 2010.

29. Yamamoto K, Ichijo $\mathrm{H}$ and Korsmeyer SJ: BCL-2 is phosphorylated and inactivated by an ASK1/Jun N-terminal protein kinase pathway normally activated at $\mathrm{G}_{2} / \mathrm{M}$. Mol Cell Biol 19: 8469-8478, 1999.

30. Scorrano L and Korsmeyer SJ: Mechanisms of cytochrome $c$ release by proapoptotic BCL-2 family members. Biochem Biophys Res Commun 304: 437-444, 2003.

31. Yu SW, Wang H, Poitras MF, Coombs C, Bowers WJ, Federoff HJ, Poirier GG, Dawson TM and Dawson VL: Mediation of poly(ADP-ribose) polymerase-1-dependent cell death by apoptosis-inducing factor. Science 297: 259-263, 2002.

32. Alabsi AM, Ali R, Ali AM, Harun H, Al-Dubai SA, Ganasegeran K, Alshagga MA, Salem SD and Abu Kasim NH: Induction of caspase-9, biochemical assessment and morphological changes caused by apoptosis in cancer cells treated with goniothalamin extracted from Goniothalamus macrophyllus. Asian Pac J Cancer Prev 14: 6273-6280, 2013.

33. Stokoe D, Stephens LR, Copeland T, Gaffney PR, Reese CB, Painter GF, Holmes AB, McCormick F and Hawkins PT: Dual role of phosphatidylinositol-3,4,5-trisphosphate in the activation of protein kinase B. Science 277: 567-570, 1997. 
34. Fang XY, Chen W, Fan JT, Song R, Wang L, Gu YH, Zeng GZ, Shen Y, Wu XF, Tan NH, et al: Plant cyclopeptide RA-V kills human breast cancer cells by inducing mitochondria-mediated apoptosis through blocking PDK1-AKT interaction. Toxicol Appl Pharmacol 267: 95-103, 2013.

35. Yoon S and Seger R: The extracellular signal-regulated kinase: Multiple substrates regulate diverse cellular functions. Growth Factors 24: 21-44, 2006.

36. Dunn KL, Espino PS, Drobic B, He S and Davie JR: The Ras-MAPK signal transduction pathway, cancer and chromatin remodeling. Biochem Cell Biol 83: 1-14, 2005.

37. Eferl R and Wagner EF: AP-1: A double-edged sword in tumorigenesis. Nat Rev Cancer 3: 859-868, 2003.

38. Ohsumi Y: Molecular dissection of autophagy: Two ubiquitinlike systems. Nat Rev Mol Cell Biol 2: 211-216, 2001.

39. Mukhopadhyay S, Panda PK, Sinha N, Das DN and Bhutia SK: Autophagy and apoptosis: Where do they meet? Apoptosis 19: 555-566, 2014.

40. Maiuri MC, Zalckvar E, Kimchi A and Kroemer G: Self-eating and self-killing: Crosstalk between autophagy and apoptosis. Nat Rev Mol Cell Biol 8: 741-752, 2007.

41. Mizushima N, Yoshimori T and Levine B: Methods in mammalian autophagy research. Cell 140: 313-326, 2010.
42. Lin C, Tsai SC, Tseng MT, Peng SF, Kuo SC, Lin MW, Hsu YM, Lee MR, Amagaya S, Huang WW, et al: AKT serine/threonine protein kinase modulates baicalin-triggered autophagy in human bladder cancer T24 cells. Int J Oncol 42: 993-1000, 2013.

43. Qin Y, Zhou ZW, Pan ST, He ZX, Zhang X, Qiu JX, Duan W, Yang T and Zhou SF: Graphene quantum dots induce apoptosis, autophagy, and inflammatory response via p38 mitogen-activated protein kinase and nuclear factor- $\mathrm{\kappa B}$ mediated signaling pathways in activated THP-1 macrophages. Toxicology 327 62-76, 2015.

44. Ding YH, Zhou ZW, Ha CF, Zhang XY, Pan ST, He ZX, Edelman JL, Wang D, Yang YX, Zhang X, et al: Alisertib, an Aurora kinase A inhibitor, induces apoptosis and autophagy but inhibits epithelial to mesenchymal transition in human epithelial ovarian cancer cells. Drug Des Devel Ther 9: 425-464, 2015.

45. Wei Y, Pattingre S, Sinha S, Bassik M and Levine B: JNK1-mediated phosphorylation of Bcl-2 regulates starvationinduced autophagy. Mol Cell 30: 678-688, 2008.

46. Zhou YY, Li Y, Jiang WQ and Zhou LF: MAPK/JNK signalling: A potential autophagy regulation pathway. Biosci Rep 35: pii: e00199, 2015. doi: 10.1042/BSR20140141. 